\title{
Bioactive Lipids and Lipidomics
}

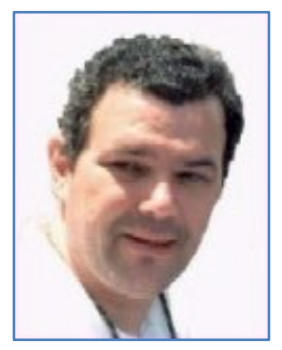

\author{
Jesús Balsinde \\ Arachidonic Acid Mobilization by Stimuli of the Innate Immune Response \\ Phospholipase $\mathrm{A}_{2}$, Eicosanoid Metabolism, Unsaturated Fatty Acid, Cyclooxygenase. \\ Phone: +34-983-423-062 (Office) \\ Phone:+34-983-184-834 (Lab) \\ Lab Page: www.balsinde.org
}

Work in our laboratory aims at understanding different aspects of the regulation of eicosanoid biosynthesis in cells of immunoinflammatory origin. The eicosanoids are a family of substances with strong pro-inflammatory activity that derive from the enzymatic oxygenation of arachidonic acid (AA). Prostaglandins, leukotrienes, lipoxins, are all members of the eicosanoid family. In cells, AA seldom occurs in free fatty acid form, and is almost always found esterified at the sn-2 position of glycerophospholipids. Thus, it has to be removed from there before any eicosanoid synthesis can occur. The enzymes involved in such a removal are the phospholipase $\mathrm{A}_{2} \mathrm{~S}$. Our laboratory devotes a special emphasis to understanding the regulation of phospholipase $\mathrm{A}_{2}$ in cells exposed to stimuli of the innate immune response.

Another family of enzymes that we are interested in is the cyclooxygenase familiy, of which there are only two members in mammalian cells. We are currently studying the one called cyclooxygenase-2, an enzyme whose expression is greatly induced during inflammation. Cyclooxygenase-2 catalyzes the addition of two oxygen molecules in to $A A$, to form prostaglandin $G_{2}$ first, and later prostaglandin $\mathrm{H} 2$. The latter is the universal precursor of all other prostaglandin molecules. We are particularly interested in the regulation of cyclooxygenase-2 induction by proinflammatory lipid mediators that are produced downstream of phospholipase $\mathrm{A}_{2}$ activation. To elucidate the different lipid mediators produced under the different conditions we utilize state-of-the-art mass spectrometry techniques.

Finally, our laboratory is also interested in the design, synthesis and assay of molecules with anti-phospholipase $A_{2}$ activity. We study inhibitors of different chemical structures in an attempt to define structure-activity relationships. To this end we have developed specific assay systems and plan to utilize animal models as well.

In summary, our group utilizes a variety of experimental techniques, from cellular biochemistry and molecular cell biology to organic chemistry and mass spectrometry to study diverse pathophysiological situations that involve the participation of proinflammatory lipid mediators.

\section{REFERENCES}

1. Pérez, R., Balboa, M. A. \& Balsinde, J. (2006) Involvement of group VIA calcium-independent phospholipase $A_{2}$ in macrophage engulfment of hydrogen peroxide-treated U937 cells. J. Immunol. 176: 2555-2561.

2. Casas, J., Gijón, M. A., Vigo, A. G., Sánchez Crespo, M., Balsinde, J., \& Balboa, M. A. (2006) Overexpression of cytosolic group IVA phospholipase $A_{2}$ protects cells from calcium-dependent death. J. Biol. Chem. 281: 6106-6116.

3. Pérez, R., Melero, R., Balboa, M. A. \& Balsinde, J. (2004) Role of group VIA calcium-independent phospholipase A $_{2}$ in arachidonic acid release, phospholipid fatty acid incorporation, and apoptosis in U937 cells responding to hydrogen peroxide. J. Biol. Chem. 279: 40385-40391.

4. Balboa, M. A., Pérez, R. \& Balsinde, J. (2003) Amplification mechanisms of inflammation: paracrine stimulation of arachidonic acid mobilization by secreted phospholipase $A_{2}$ is regulated by cytosolic phospholipase $A_{2}$-derived hydroperoxyeicosatetraenoic acid. J. Immunol. 171: 989-994.

5. Balboa, M. A., Sáez, Y. \& Balsinde, J. (2003) Calcium-independent phospholipase $A_{2}$ is required for lysozyme secretion in U937 promonocytes. J. Immunol. 170: 5276-5280.

6. Fuentes, L., Pérez, R., Nieto, M.L., Balsinde, J., \& Balboa, M.A.(2003) Bromoenol lactone promotes cell death by a mechanism involving phosphatidate phosphohydrolase-1 rather than calcium-independent phospholipase $\mathrm{A}_{2}$. J. Biol. Chem. 278: 48059-48065.

7. Balboa, M. A. \& Balsinde, J. (2002) Involvement of calcium-independent phospholipase $A_{2}$ in hydrogen peroxide-induced accumulation of free fatty acids in human U937 cells. J. Biol. Chem. 277: 40384-40389.

8. Balsinde, J. (2002) Roles of various phospholipases $A_{2}$ in providing lysophospholipid acceptors for fatty acid phospholipid incorporation and remodelling. Biochem. J. 364: 695-702. 